\title{
Effects of temperature and digestion on the swimming performance of juvenile Chinese bream
}

\author{
Jing Peng, Zhen-Dong Cao, Shi-Jian Fu*
}

Laboratory of Evolutionary Physiology and Behaviour, Chongqing Key Laboratory of Animal Biology, Chongqing Normal University, Chongqing 401331, PR China

\begin{abstract}
Fish that are active foragers usually perform routine activities while digesting their food; thus, postprandial swimming capacity might be ecologically important. To test whether digestion affected swimming performance in an active forager and whether the possible effects varied with temperature, we investigated the critical swimming speed $\left(U_{\text {crit }}\right)$ and the resting and active metabolic rate $\left(\mathrm{MO}_{2}\right)$ of fasted and fed juvenile Chinese bream Parabramis pekinensis after $30 \mathrm{~d}$ exposure to 3 temperatures $\left(15,20\right.$, and $\left.25^{\circ} \mathrm{C}\right)$. In fasted fish, $U_{\text {crit, }}$ resting and active $\mathrm{MO}_{2}$ all increased with temperature. Digestion elicited a significant increase in $\mathrm{MO}_{2}$, which was enhanced at higher temperatures. Compared to fasted fish, fed fish exhibited significantly lower $U_{\text {crit }}$ in both the 25 and $20^{\circ} \mathrm{C}$ groups, whereas no significant difference in $U_{\text {crit }}$ was observed between fasted and fed fish in the $15^{\circ} \mathrm{C}$ group. Furthermore, digestion resulted in a significantly higher active $\mathrm{MO}_{2}$ in the $15^{\circ} \mathrm{C}$ group, whereas no significant difference in active $\mathrm{MO}_{2}$ was observed between fasted and fed fish in the 20 and $25^{\circ} \mathrm{C}$ groups. This suggests that the bream adopted an additive metabolic mode, i.e. digestion and swimming were performed independently at low temperatures, but shifted to a digestion-priority mode at higher temperatures due to a shortage of oxygen resulting from an increased digestive and locomotive oxygen demand. The present study contradicted our hypothesis that an active cyprinid with high swimming performance would give priority to locomotion when the oxygen supply was insufficient to meet the metabolic demands of both digestion and swimming.
\end{abstract}

KEY WORDS: Digestion - Metabolic mode - Metabolic priority - Swimming performance · Temperature

\section{INTRODUCTION}

Swimming is an important physiological activity for fish because it is closely related to food capture, predator avoidance and reproductive behavior (Brett 1964, Blake 2004, Kieffer 2010, Cai et al. 2014a). Fish may perform swimming activities while digesting their food, and the outcome of the competition between the processes of digestion and swimming has important ecological relevance because both activities are important fitness-determining physiological functions in fish species. This competition might be increasingly severe in active foragers and in those fish species living in a highly demanding habitat (e.g. high water

${ }^{*}$ Corresponding author: shijianfu9@hotmail.com velocity or predation stress). Recently, the competition between digestion and swimming under a postprandial locomotion status has drawn the attention of scientists (Alsop \& Wood 1997, Thorarensen \& Farrell 2006, Altimiras et al. 2008, Fu et al. 2009, JourdanPineau et al. 2010, Cai et al. 2014b). These 2 physiological activities can be performed independentlythe so-called additive metabolic mode found in fish species such as the common carp Cyprinus carpio (Pang et al. 2011) and the European sea bass Dicentrarchus labrax (Altimiras et al. 2008, Jourdan-Pineau et al. 2010). Otherwise, the digestion process may defer to swimming (locomotion-priority mode), as in qingbo Spinibarbus sinensis (Pang et al. 2011), or vice

() The authors 2014. Open Access under Creative Commons by Attribution Licence. Use, distribution and reproduction are unrestricted. Authors and original publication must be credited. 
versa (digestion-priority mode) as in goldfish Carassius auratus (Pang et al. 2011), rainbow trout Oncorhynchus mykiss (Alsop \& Wood 1997) and Chinook salmon O. tshawytscha (Thorarensen \& Farrell 2006).

The physiological mechanisms, ecological causes and selective agents underlying the different metabolic modes among fish species are largely unknown. We previously suggested that the metabolic mode employed might be related to the ecological habitat of the individual species (Pang et al. 2011); i.e. high performance swimmers evolved under selective stress for high swimming demand, and therefore digestion should give priority to swimming when the metabolic supply is insufficient to meet the metabolic demands (and vice versa). However, only 3 cyprinids have been investigated thus far with regards to metabolic mode. In this study, we investigated the metabolic mode in Chinese bream Parabramis pekinensis, a widely distributed cyprinid in China with high swimming performance (Yan et al. 2013).

It has been suggested that the metabolic mode may vary with environmental conditions such as temperature and dissolved oxygen levels in some (but not all) fish species (Pang et al. 2011, Zhang et al. 2012). The competition between digestion and swimming is resolved by their relative roles within a given species, and by the conservative capacities of the central cardio-respiratory system (oxygen supply) and the peripheral digestive and locomotory systems (metabolic demands). The change in metabolic mode results from a shift in the balance point between oxygen supply and the metabolic demands of digestion and locomotion in different environments.

Temperature has a profound effect on all physiological functions, including cardio-respiratory capacity, digestion and swimming performance (Fry 1971, Kieffer et al. 1994, Luo \& Xie 2008, Zeng et al. 2009). Furthermore, oxygen availability also changes with temperature, which may profoundly affect metabolic competition in fish species (Pang et al. 2011). Therefore, we selected 3 experimental temperatures to test whether the metabolic mode changed with temperature in Chinese bream. This species spends more than $30 \%$ of its time moving in either a fasting or digesting status, i.e. it is an active forager that frequently forages or swims while digesting food. Furthermore, its habitat exhibits profound seasonal thermal changes and daily fluctuations. We selected 15,20 and $25^{\circ} \mathrm{C}$, which simulate the mean of summer, autumn and winter temperatures of local water bodies. Our aim was to test whether digestion had a significant effect on the swimming performance of this active forager, and if so, whether such effects varied with temperature.

\section{MATERIALS AND METHODS}

\section{Experimental animals and acclimation}

Juvenile Chinese bream were obtained from a local farmer and kept in $20^{\circ} \mathrm{C}$ de-chlorinated, fully aerated tap water tanks for $2 \mathrm{wk}$ prior to the experiment. The photoperiod was maintained at 12:12 $\mathrm{h}$ light:dark cycle, and the oxygen level was kept above $8 \mathrm{mg} \mathrm{l}^{-1}$. One-tenth of the water in each tank was replaced daily with fresh water. Throughout the experimental period, the fish were fed twice daily (at 09:00 and 17:00 h) to satiation with a commercial food (Tongwei; dietary composition: $41.2 \pm 0.9 \%$ protein; $8.5 \pm 0.5 \%$ lipid; $25.7 \pm 1.2 \%$ carbohydrate and $12.3 \pm 0.4 \%$ ash). The uneaten food and feces were removed with a siphon $1 \mathrm{~h}$ after feeding. All of the experiments were conducted according to the Guidelines on the Humane Treatment of Laboratory Animals established by the Ministry of Science and Technology of the People's Republic of China.

\section{Experimental design}

Three experimental temperatures $\left(15,20\right.$ and $\left.25^{\circ} \mathrm{C}\right)$ were used. After acclimation, juvenile Chinese bream were transferred from the general holding tanks to experimental tanks. The water temperature was kept constant $\left(20^{\circ} \mathrm{C}\right.$ ), increased (to $25^{\circ} \mathrm{C}$ ) or decreased (to $15^{\circ} \mathrm{C}$ ) by $1^{\circ} \mathrm{C} \mathrm{d}^{-1}$ until it reached the experimental treatment temperature (Pang et al. 2011). The fish were maintained at the experimental temperature for $30 \mathrm{~d}$ and fed to satiation twice daily as during the acclimation period.

For the fasting experiment group, after $1 \mathrm{~d}$ of fasting, 8 fish from each temperature group were introduced into a swim tunnel and held for $2 \mathrm{~h}$ at a water speed of $3.5 \mathrm{~cm} \mathrm{~s}^{-1}$ for acclimation ( 0.5 body length [BL] $\mathrm{s}^{-1}$, which was enough for full water exchange but elicited no apparent swimming activity) (Pang et al. 2011). The metabolic rate $\left(\mathrm{MO}_{2}, \mathrm{mg} \mathrm{O}_{2} \mathrm{~kg}^{-1} \mathrm{~h}^{-1}\right)$ was then measured and recorded as 'resting $\mathrm{MO}_{2}$ ' (see details in 'Experimental facility and measurements' below). Individual fish were then tested using a ramp- $U_{\text {crit }}$ test (Jain \& Farrell 2003). This test involved increasing the water speed to $50 \%$ of the critical swimming speed ( $U_{\text {crit }}$ ) as determined by a pilot experiment $\left(35 \mathrm{~cm} \mathrm{~s}^{-1}\right.$ at 15 or $20^{\circ} \mathrm{C}$, and $42 \mathrm{~cm}$ $\mathrm{s}^{-1}$ at $25^{\circ} \mathrm{C}$ ) over a $2 \mathrm{~min}$ period, after which time the water speed was increased in $7 \mathrm{~cm} \mathrm{~s}^{-1}$ increments every 20 min until the fish became exhausted. Testing was terminated when the fish failed to move off 
the rear honeycomb screen of the swimming chamber after 20 s (Jain \& Farrell 2003, Lee et al. 2003, Pang et al. 2011). The maximum measured $\mathrm{MO}_{2}$ during the ramp- $U_{\text {crit }}$ test was defined as 'active $\mathrm{MO}_{2}{ }^{\prime}$. Dissolved oxygen concentration values were measured throughout the whole ramp- $U_{\text {crit }}$ test using a HQ30 oxygen probe (Hach).

For the fed fish, another 8 fish were selected from each temperature treatment group, slightly anesthetized with neutralized tricaine methane sulfonate (MS-222, $30 \mathrm{mg} \mathrm{l}^{-1}$ ) and force-fed with approximately $3 \%$ body-mass, meal-sized diets (satiated feeding) by a gavage protocol (Altimiras et al. 2008, Li et al. 2010). The fed fish were then transferred to the swimming chamber and allowed to recover for $2 \mathrm{~h}$; following recovery, $U_{\text {crit }}$ was measured in the same manner as for the fasting groups. The $2 \mathrm{~h}$ recovery period was determined by the digestion process of Chinese bream (the duration of the digestion process is $8 \mathrm{~h}$, and the postprandial metabolic response peaks approximately $4 \mathrm{~h}$ after feeding, thus the metabolic competition between digestion and swimming is likely most severe during $U_{\text {crit }}$ testing).

\section{Experimental facility and measurements}

A Brett-type swim tunnel respirometer was used to measure fish $U_{\text {crit }}$ and $\mathrm{MO}_{2}$ as a function of swimming speed (for details of the respirometer, see Li et al. 2010 and Pang et al. 2011). Fish were placed downstream of the propeller in a swimming chamber with an area of approximately $20 \mathrm{~cm}^{2}$. The water temperature in the swimming chamber was controlled within $\pm 0.2^{\circ} \mathrm{C}$ by a water bath connected to a stainless steel heat exchanger. $U_{\text {crit }}$ was calculated for individual fish using Brett's equation (Brett 1964):

$$
U_{\text {crit }}=V+(t / T) \Delta V
$$

where $v$ is the highest speed at which the fish swam for the full time period $\left(\mathrm{cm} \mathrm{s}^{-1}\right), \Delta v$ is the velocity increment $\left(7 \mathrm{~cm} \mathrm{~s}^{-1}\right), T$ is the constant period of swimming per speed (20 min), and $t$ is the time that the fish swam at the final speed (min). All absolute $U_{\text {crit }}$ values $\left(\mathrm{cm} \mathrm{s}^{-1}\right)$ were converted to body length per second $\left(\mathrm{BL} \mathrm{s}{ }^{-1}\right)$, which denotes relative $U_{\text {crit }}$.

A small fraction of the water from the sealed respirometer was siphoned past the probe of the HQ30 oximeter in a chamber thermoregulated by a water bath. The water oxygen concentration $\left(\mathrm{mg} \mathrm{l}^{-1}\right)$ was recorded once every $2 \mathrm{~min}$. In open mode, the respirometer was supplied with fully aerated and thermoregulated water that circulated in a reservoir tank. In closed mode, the standardized $\mathrm{MO}_{2}$ of an individual swimming fish was calculated from the depletion of oxygen according to the following equation (Fu et al. 2009):

$$
\mathrm{MO}_{2}=60 \text { slope } \mathrm{V} / \mathrm{m}^{0.75}
$$

where slope is the decrease in the water oxygen content per minute $\left(\mathrm{mg} \mathrm{O} \mathrm{O}_{2} \mathrm{~min}^{-1}\right)$ obtained from linear regressions of time (min) and water oxygen content $\left(\mathrm{mg} \mathrm{l}^{-1}\right)$ using a statistical program (Excel 2003). Only slopes with $\mathrm{r}^{2}>0.95$ were considered in the analysis. $V$ is the total volume of the respirometer (3.5 l) minus the volume of the fish, and $m$ is the body mass of the fish $(\mathrm{kg})$. The water oxygen content in the respirometer was never allowed to fall below $85 \%$ oxygen saturation (Claireaux et al. 2006).

\section{Data analysis}

All values are presented as means $\pm \mathrm{SE}$; results were considered significant at $\mathrm{p}<0.05$. The effect of temperature and digestion on $U_{\text {crit }}$ (body length as the covariate), resting $\mathrm{MO}_{2}$ and active $\mathrm{MO}_{2}$ (body mass as the covariate) was determined by a 2-way ANCOVA. The effect of temperature, swimming speed, and digestion on $\mathrm{MO}_{2}$ was determined by a 3-way repeated measures ANOVA. The ANOVA was followed by a Duncan multiple-comparison test or a $t$-test when it was necessary to determine the difference between the values of the different treatment groups.

\section{RESULTS}

\section{Resting $\mathrm{MO}_{2}$}

Neither body mass nor body length significantly differed among the fish in the experimental groups (Table 1). Both temperature and digestion showed significant effects on resting $\mathrm{MO}_{2}(\mathrm{p}<0.001)$ (Table 2). In fasted fish, resting $\mathrm{MO}_{2}$ increased with temperature, and a significant difference was found among all 3 temperature groups ( $p<0.001$ ) (Fig. 1a). After feeding, the fish in all groups showed a significant increase in resting $\mathrm{MO}_{2}(\mathrm{p}<0.001)$, and the digestionelicited $\mathrm{MO}_{2}$ increment increased with temperature (interaction effect, $\mathrm{p}=0.007$ ).

$$
\boldsymbol{U}_{\text {crit }}
$$

Both temperature and digestion showed significant effects on $U_{\text {crit }}(\mathrm{p}<0.05)$. In fasted fish, $U_{\text {crit }}$ increased 
Table 1. Body sizes of Chinese bream Parabramis pekinensis (mean $\pm \mathrm{SE}, \mathrm{n}=8$ ) used in the temperature experiments

\begin{tabular}{|c|c|c|c|c|}
\hline & $\begin{array}{r}\text { Fa } \\
\text { Body mass } \\
(\mathrm{g})\end{array}$ & $\begin{array}{l}\text { sted } \\
\text { Body length } \\
\quad(\mathrm{cm})\end{array}$ & $\begin{array}{l}\mathrm{Fe} \\
\text { Body mass } \\
(\mathrm{g})\end{array}$ & $\begin{array}{l}\text { ed } \\
\text { Body length } \\
\qquad(\mathrm{cm})\end{array}$ \\
\hline $15^{\circ} \mathrm{C}$ & $7.07 \pm 0.32$ & $7.36 \pm 0.12$ & $8.27 \pm 0.43$ & $7.71 \pm 0.11$ \\
\hline $20^{\circ} \mathrm{C}$ & $7.62 \pm 0.58$ & $7.34 \pm 0.16$ & $7.52 \pm 0.23$ & $7.59 \pm 0.17$ \\
\hline $25^{\circ} \mathrm{C}$ & $8.53 \pm 0.36$ & $7.71 \pm 0.12$ & $8.74 \pm 0.32$ & $7.89 \pm 0.10$ \\
\hline $\mathrm{df}$ & 2,21 & 2,21 & 2,23 & 2,23 \\
\hline$F$ & 3.271 & 2.899 & 3.347 & 1.336 \\
\hline $\mathrm{p}$ & 0.058 & 0.077 & 0.055 & 0.284 \\
\hline
\end{tabular}

with temperature (Fig. 1b). After feeding, $U_{\text {crit }}$ in both the 25 and $20^{\circ} \mathrm{C}$ temperature groups decreased significantly, whereas $U_{\text {crit }}$ in the $15^{\circ} \mathrm{C}$ temperature group showed no significant change after feeding.

\section{Active $\mathrm{MO}_{2}$}

Temperature had a significant effect on the active $\mathrm{MO}_{2}(\mathrm{p}<0.001)$. In fasted fish, the active $\mathrm{MO}_{2}$ values of the 25 and $20^{\circ} \mathrm{C}$ temperature groups were significantly higher than that of the $15^{\circ} \mathrm{C}$ temperature group $(\mathrm{p}<0.05)$ (Fig. 1c). After feeding, only the $15^{\circ} \mathrm{C}$ temperature group showed a significantly higher active $\mathrm{MO}_{2}$ compared to fasted fish; digestion had no effect on active $\mathrm{MO}_{2}$ in the other 2 temperature groups.

\section{Swimming speed: $\mathrm{MO}_{2}$ profile}

$\mathrm{MO}_{2}$ increased significantly with swimming speed in all groups ( $\mathrm{p}<0.001$ ) (Fig. 2). Digestion caused a significant increase in $\mathrm{MO}_{2}$ when the fish swam at any given speed in the $15^{\circ} \mathrm{C}$ temperature group; however, compared to fasted fish, fed fish in the 25 and $20^{\circ} \mathrm{C}$ temperature groups only showed a significantly higher $\mathrm{MO}_{2}$ at low swimming speeds.

Table 2. Effect of temperature and digestion on critical swimming performance $\left(U_{\text {crit }}\right)$ and resting and active oxygen consumption rate $\left(\mathrm{MO}_{2}\right)$ in Chinese bream Parabramis pekinensis based on a 2-way analysis of covariance

\begin{tabular}{|lrrrrrrrr|}
\hline & df & \multicolumn{2}{c}{ Resting $\mathrm{MO}_{2}$} & \multicolumn{3}{c}{$U_{\text {crit }}$} & \multicolumn{2}{c}{ Active $\mathrm{MO}_{2}$} \\
& & $F$ & $\mathrm{p}$ & $F$ & $\mathrm{p}$ & $F$ & $\mathrm{p}$ \\
\hline Covariate & 1,41 & 0.225 & 0.638 & 9.453 & 0.004 & 0.007 & 0.932 \\
Temp. (T) & 2,41 & 32.20 & $<0.001$ & 4.932 & 0.011 & 14.22 & $<0.001$ \\
Digestion (D) & 1,41 & 59.06 & $<0.001$ & 0.482 & 0.491 & 0.423 & 0.519 \\
T $\times$ D & 2,41 & 3.381 & 0.044 & 5.119 & 0.010 & 5.110 & 0.010 \\
\hline
\end{tabular}

\section{DISCUSSION}

\section{Swimming performance}

The $U_{\text {crit }}$ of the Chinese bream Parabramis pekinensis in our experiments was between 9.67 and 10.86 $\mathrm{BL} \mathrm{s}^{-1}$ depending on experimental temperature; swimming resulted in a 4 - to 6 -fold increase in $\mathrm{MO}_{2}$ compared to the resting status of the fish. These are among the highest values documented in cyprinids (Yan et al. 2013). However, after consumption of a satiated meal in this study, postprandial $\mathrm{MO}_{2}$ only increased by $50 \%$ compared to fasted individuals, which is one of the lowest postprandial metabolic increases among all published data (Jobling et al. 1981, Alsop \& Wood 1997, Pang et al. 2011). Chinese bream is thus a typical model of the so-called locomotion-metabolic type of fish (i.e. fish species with a high locomotive but low digestive metabolism; Priede 1985). Chinese bream frequently forage on grass of low nutritive value in either open water bodies with a high risk of predation or in rivers with rapid currents. Laboratory observation revealed that both fed and fasting Chinese bream spend more than $30 \%$ of their time spontaneously moving (J. Peng \& S. J. Fu pers. obs.). Thus, selection may favor high swimming performance over digestive performance in this species.

In this study, all variables increased significantly with the increase in experimental temperature. However, thermal sensitivity varied profoundly among the different variables. With a temperature increase from 15 to $25^{\circ} \mathrm{C}$, resting $\mathrm{MO}_{2}$ increased by $106 \%$ and active $\mathrm{MO}_{2}$ increased by $43 \%$, whereas $U_{\text {crit }}$ only increased by $12 \%$. The change in resting $\mathrm{MO}_{2}$ is similar to other cyprinids such as goldfish and common carp (100 to $130 \%$ ), but higher than qingbo and crucian carp Carassius auratus (ca. 50\% for both species; Pang et al. 2011, He et al. 2014). Although anaerobic metabolism is involved to some extent during $U_{\text {crit }}$ measurement, it is generally acknowledged that $U_{\text {crit }}$ is largely an aerobic swimming indicator and closely related to maximum aerobic capacity, i.e. active $\mathrm{MO}_{2}$. Thus, $U_{\text {crit }}$ theoretically possesses a positive relationship with active $\mathrm{MO}_{2}$. In the present study, the unparalleled change between $U_{\text {crit }}$ and active $\mathrm{MO}_{2}$ lay in the decreased swimming efficiency at higher temperature as a result of increased resting $\mathrm{MO}_{2}$. Furthermore, energy expenditure (hence $\mathrm{MO}_{2}$ ) increased exponentially with swimming 

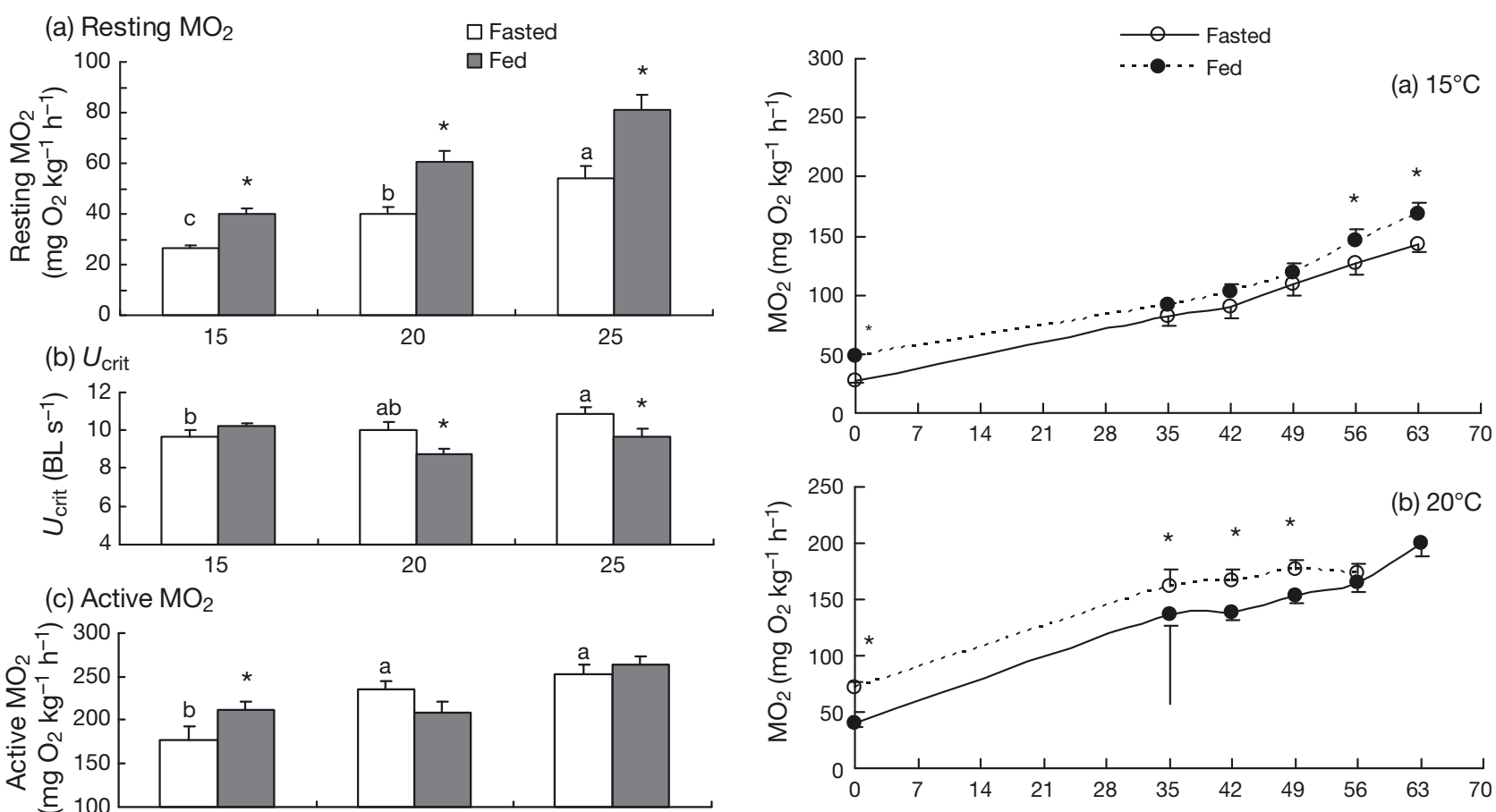

(c) Active $\mathrm{MO}_{2}$

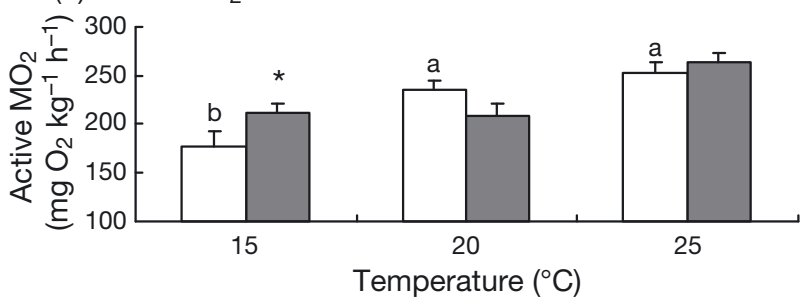

Fig. 1. Effects of temperature and digestion on (a) resting oxygen consumption rate $\left(\mathrm{MO}_{2}\right)$, (b) critical swimming speed $\left(U_{\text {crit }}\right)$, and (c) active $\mathrm{MO}_{2}$ in juvenile Chinese bream Parabramis pekinensis. Data are mean $\pm \mathrm{SE}(\mathrm{n}=8)$; see Table 1 for information on fish sizes. Letters above white bars indicate significant differences among experimental temperatures in fasted fish; $\left({ }^{*}\right)$ above shaded bars denotes a significant difference $(p<0.05)$ in variables between fasted and fed fish in a given temperature treatment group. BL: body lengths

speed, resulting in a more profound increase in active $\mathrm{MO}_{2}$ than $U_{\text {crit }}$ with the increase in experimental temperature.

The nonparallel increase between resting $\mathrm{MO}_{2}$ and swimming performance was unexpected. The high swimming performance may be driven by a high selective stress for swimming demand. Thus, swimming performance might be more closely related to maintenance metabolism than to digestive performance at varied acclimation temperatures. However, the active $\mathrm{MO}_{2}$, and hence $U_{\text {crit, }}$ increased much less than the resting $\mathrm{MO}_{2}$. This suggests that the increased maintenance metabolism may contribute more than locomotion to physiological function. For example, postprandial $\mathrm{MO}_{2}$ increased by $100 \%$ with a temperature increase from 15 to $25^{\circ} \mathrm{C}$, similar to the resting $\mathrm{MO}_{2}$ in Chinese bream. This result may indicate that the digestive capacity of Chinese bream improved more than swimming performance as the temperature became optimum. However, when considering the metabolic increase solely on the basis

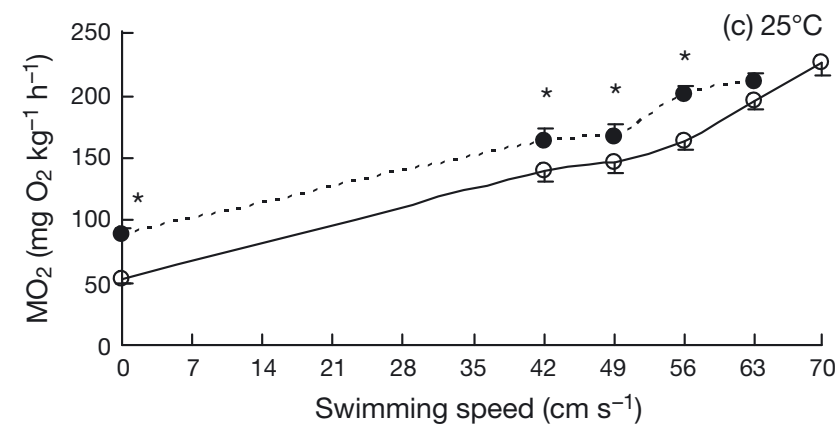

Fig. 2. Effects of digestion on oxygen consumption rate $\left(\mathrm{MO}_{2}\right)$ of Chinese bream Parabramis pekinensis at progressively increasing water velocities under experimental temperatures of (a) $15^{\circ} \mathrm{C}$, (b) $20^{\circ} \mathrm{C}$ and (c) $25^{\circ} \mathrm{C}$. Data are mean $\pm \mathrm{SE}(\mathrm{n}=8) .\left({ }^{*}\right)$ denotes a significant difference $(\mathrm{p}<$ $0.05)$ in $\mathrm{MO}_{2}$ between fasted and fed fish at a given swimming speed; see Table 1 for information on fish sizes

of digestion or locomotion, Chinese bream demonstrated a similar low digestive performance among the experimental temperatures, whereas the high swimming performance was mostly maintained at the low temperature. This is the reason that swimming performance cannot improve considerably as the temperature increases - swimming performance is more conservative at low temperatures. This is in agreement with a previous study that documented that Chinese bream gill morphology remained unchanged at low temperatures, while it (and hence the respiratory capacity) was reduced in other cyprinids (Chen 2011). In addition, while the glycogen recruitment and lactate clearance capacity decreased 
at low temperatures in crucian carp, Chinese bream demonstrated unusually higher glycogen recruitment and lactate clearance capacities at low temperatures (He et al. 2014).

\section{Effect of digestion}

We found no difference in $U_{\text {crit }}$ between fasted and fed fish at $15^{\circ} \mathrm{C}_{i}$ the active $\mathrm{MO}_{2}$ of fed fish was higher than that of fasted fish, and the digestion-elicited $\mathrm{MO}_{2}$ increase can be added to swimming $\mathrm{MO}_{2}$ total until the $U_{\text {crit }}$ is reached. These results indicate that at low temperature, digestion and locomotion can be performed independently, i.e. Chinese bream exhibit an additive mode at low temperatures. This characteristic may due to a high oxygen uptake capacity resulting from a lack of down-regulation of gill morphology (Chen 2011), high tissue metabolite recruitment (He et al. 2014), low digestive performance, and high environmental oxygen availability at low temperatures. This agrees with all 3 cyprinids and southern catfish measured at $15^{\circ} \mathrm{C}$ (Pang et al. 2010, 2011). However, cold-water fish species, low temperature-acclimated Chinook salmon $\left(10^{\circ} \mathrm{C}\right)$, and rainbow trout $\left(15^{\circ} \mathrm{C}\right)$ all showed a digestion-priority mode (Alsop \& Wood 1997, Thorarensen \& Farrell 2006).

With increased temperature, both the resting $\mathrm{MO}_{2}$ of fed fish and the active $\mathrm{MO}_{2}$ of fasted fish increased, whereas the active $\mathrm{MO}_{2}$ of fed fish showed no increase. Thus, the oxygen uptake capacity (as indicated by the postprandial active $\mathrm{MO}_{2}$ ), and hence metabolic supply, is not enough to balance the oxygen demand during postprandial locomotion. One physiological function must be sacrificed to the other to some extent at a higher temperatures; as previously demonstrated in southern catfish, qingbo, and goldfish (Pang et al. 2010, 2011). It has been suggested that for fish with a high digestive performance (e.g. southern catfish and goldfish), locomotion would yield priority to digestion, while for fish with high locomotive performance, digestion would give way to locomotion as competition between digestion and locomotion becomes severe (Pang et al. 2011). However, contrary to our expectation, locomotion was sacrificed to digestion at the higher temperatures in Chinese bream, as $U_{\text {crit }}$ decreased by 12 and $11 \%$ at 20 and $25^{\circ} \mathrm{C}$ experimental temperatures, respectively. This finding may be related to some conservative morphological or physiological characteristics showing genetic constraints.

For some fish species, once nutrients from food have reached the digestive tissues, the metabolic processes cannot be turned off, while other fish can regulate their physiological process by shifting oxygen delivery, metabolic fuel and/or waste products via blood flood (Alsop \& Wood 1997, Altimiras et al. 2008). Furthermore, because none of the previous investigations of metabolic mode (including this study) measured the digestive performance (e.g. evacuation rate) during swimming, it is possible that digestion does yield its priority to locomotion. At 20 and $25^{\circ} \mathrm{C}$, the $\mathrm{MO}_{2}$ of both the fed and fasted fish showed no significant difference at 56 and $63 \mathrm{~cm} \mathrm{~s}^{-1}$, suggesting that the digestion-induced $\mathrm{MO}_{2}$ increment also decreased at high swimming speeds. A previous study on goldfish suggested that decreased swimming efficiency is a result of physiological and/or morphological changes in postprandial fish rather than a competition for oxygen supply, which resulted in the decreased $U_{\text {crit }}$ during digestion (Fu et al. 2013). Nevertheless, because Chinese bream are capable of high swimming speeds, a decrease in $U_{\text {crit }}$ of 11 or $12 \%$ may not have significant negative ecological consequences.

\section{Concluding remarks}

The physiological priority, and hence the metabolic mode, may be shaped during long-term evolution depending on the costs and benefits of maintaining either locomotion or digestion during postprandial swimming, which varies profoundly among species and environmental conditions. In this study, Chinese bream demonstrated a higher swimming performance but lower digestive capacity compared to most of other cyprinids. This species maintained most of its swimming performance but demonstrated very little digestive capacity at low temperatures. Thus, the feeding metabolism increased more profoundly than active $\mathrm{MO}_{2}$ and $U_{\text {crit }}$ as the temperature rose. The feeding metabolism was added to the swimming $\mathrm{MO}_{2}$ up to the $U_{\text {crit }}$ at $15^{\circ} \mathrm{C}$, suggesting an additive metabolic mode, possibly due to low digestive and locomotive capacity but high oxygen availability at lower temperatures. However, feeding metabolism can only add to swimming $\mathrm{MO}_{2}$ at low swimming speeds, and fed fish showed a significantly low $U_{\text {crit }}$. This suggests a digestion-priority mode, possibly due to the enhanced competition between digestion and locomotion for oxygen at high temperatures.

Acknowledgements. This study was funded by the National Science Foundation of China (NSFC 31172096; 31300340) and the Key Project of the Natural Science Foundation of CQ (cstc2013jjB20003). 


\section{LITERATURE CITED}

Alsop DH, Wood CM (1997) The interactive effects of feeding and exercise on oxygen consumption, swimming performance and protein usage in juvenile rainbow trout (Oncorhynchus mykiss). J Exp Biol 200:2337-2346

Altimiras J, Claireaux G, Sandblom E, Farrell AP, McKenzie DJ, Axelsson M (2008) Gastrointestinal blood flow and postprandial metabolism in swimming sea bass Dicentrarchus labrax. Physiol Biochem Zool 81:663-672

Blake RW (2004) Fish functional design and swimming performance. J Fish Biol 65:1193-1222

Brett JR (1964) The respiratory metabolism and swimming performance of young sockeye salmon. J Fish Res Board Can 21:1183-1226

Cai L, Chen L, Johnson D, Gao Y and others (2014a) Integrating water flow, locomotor performance and respiration of Chinese sturgeon during multiple fatiguerecovery cycles. PLoS ONE 9:e94345

$>$ Cai L, Fang M, Johnson D, Lin S, Tu Z, Liu G, Huang Y (2014b) Interrelationships between feeding, food deprivation and swimming performance in juvenile grass carp. Aquat Biol 20:69-76

Chen BJ (2011) The effect of temperature on critical oxygen tension $\left(P_{\text {crit }}\right)$ and gill morphology in 6 carps. MSc thesis, Chongqing Normal University

> Claireaux G, Couturier C, Groison AL (2006) Effect of temperature on maximum swimming speed and cost of transport in juvenile European sea bass (Dicentrarchus labrax). J Exp Biol 209:3420-3428

Fry FEJ (1971) The effect of environmental factors on the physiology of fish. In: Hoar WS, Randall DJ (eds) Fish physiology. Academic Press, San Diego, CA, p 1-98

Fu SJ, Zeng LQ, Li XM, Pang X, Cao ZD, Peng JL, Wang YX (2009) The behavioral, digestive and metabolic characteristics of fishes with different foraging strategies. J Exp Biol 212:2296-2302

Fu C, Cao ZD, Fu SJ (2013) The effects of caudal fin amputation on metabolic interaction between digestion and locomotion in juveniles of 3 cyprinid fish species with different metabolic modes. Comp Biochem Physiol Part A Mol Integr Physiol 164:456-465

$>\mathrm{He}$ W, Cao ZD, Fu SJ (2014) Effect of temperature on hypoxia tolerance and its underlying biochemical mechanism in two juvenile cyprinids exhibiting distinct hypoxia sensitivity. Comp Biochem Physiol Part A Mol Integr Physiol (in press), doi:10.1016/j.cbpa.2014.05.004

$>$ Jain KE, Farrell AP (2003) Influence of seasonal temperature on the repeat swimming performance of rainbow trout Oncorhynchus mykiss. J Exp Biol 206:3569-3579

> Jobling M (1981) The influences of feeding on the metabolic rate of fishes: a short review. J Fish Biol 18:385-400

> Jourdan-Pineau H, Dupont-Prinet A, Claireaux G, McKenzie

Editorial responsibility: J. Rudi Strickler,

Milwaukee, Wisconsin, USA
DJ (2010) An investigation of metabolic prioritization in the European sea bass, Dicentrarchus labrax. Physiol Biochem Zool 83:68-77

- Kieffer JD (2010) Perspective-exercise in fish: 50+ years and going strong. Comp Biochem Physiol Part A Mol Integr Physiol 156:163-168

> Kieffer J, Currie S, Tufts B (1994) Effects of environmental temperature on the metabolic and acid-base responses of rainbow trout to exhaustive exercise. J Exp Biol 194: 299-317

Lee CG, Farrell AP, Lotto A, MacNctt MJ, Hinch SG, Healey MC (2003) The effect of temperature on swimming performance and oxygen consumption in adult sockeye (Oncorhynchus nerka) and coho (O. kisutch) salmon stocks. J Exp Biol 206:3239-3251)

Li XM, Cao ZD, Peng JL, Fu SJ (2010) The effect of exercise training on the interaction of feeding and exercise in juvenile southern catfish (Silurus meridionalis Chen). J Exp Zool 313A:557-563

> Luo YP, Xie XJ (2008) Effects of temperature on specific dynamic action of the southern catfish Silurus meridionalis. Comp Biochem Physiol Part A Mol Integr Physiol 149:150-156

Pang X, Cao ZD, Peng JL, Fu SJ (2010) The effects of feeding on the swimming performance and metabolic response of juvenile southern catfish, Silurus meridionalis, acclimated at different temperatures. Comp Biochem Physiol Part A Mol Integr Physiol 155:253-258

Pang X, Cao ZD, Fu SJ (2011) The effects of temperature on metabolic interaction between digestion and locomotion in juveniles of three cyprinid fish, Carassius auratus, Cyprinus carpio and Spinibarbus sinensis. Comp Biochem Physiol Part A Mol Integr Physiol159: 253-260

Priede IG (1985) Metabolic scope in fishes. In: Tytler P, Calow P (eds) Fish energetics: new perspective. Johns Hopkins University Press, Baltimore, MD, p 33-64

> Thorarensen H, Farrell AP (2006) Postprandial intestinal blood flow, metabolic rate, and exercise in Chinook salmon (Oncorhynchus tshawytscha). Physiol Biochem Zool 79:688-694

> Yan GJ, He XK, Cao ZD, Fu SJ (2013) An interspecific comparison between morphology and swimming performance in cyprinids. J Evol Biol 26:1802-1815

> Zeng LQ, Cao ZD, Fu SJ, Peng JL, Wang YX (2009) Effect of temperature on swimming performance in juvenile southern catfish (Silurus meridionalis). Comp Biochem Physiol Part A Mol Integr Physiol 153:125-130

Zhang W, Cao ZD, Fu SJ (2012) The effects of dissolved oxygen levels on the metabolic interaction between digestion and locomotion in Cyprinid fishes with different locomotive and digestive performances. J Comp Physiol B Biochem Syst Environ Physiol 182:641-650

Submitted: April 28, 2014; Accepted: June 20, 2014 Proofs received from author(s): August 14, 2014 